きる. $\mathrm{F}(\mathrm{h})$ は中性子散乱実験の Bragg 反射強 度から求められる. 次数 h の Bragg 散乱強度 I(h) とすると，(20)式となる.

$$
I(h) \propto|F(h)|^{2}
$$

一般に, $F(h)$ は複素数で, 振幅と位相因子が含 まれる. しかし, (20)式でわかるように, 実験で得 られるのは振幅の 2 乗した值で, 位相因子は直接 求まらない，位相因子を求める 1 つの方法はパ ターソン関数,

$$
P(x)=\frac{2}{d} \sum_{h=1}^{n}|F(h)|{ }^{2} \cos \left(\frac{2 \pi h x}{d}\right) \quad \text { (21) }
$$

を計算することである.ここで，フーリエ係数は 求められるが, 得られる結果は, すべての原子間 の相関を原点の周囲に平行移動した図形であり, 解釈はそれほど容易ではない，簡単な方法として 用いられるのは試行錯誤法である. 構造に対称中 心があると, 位相因子は $(+)$ か $(-)$ のどちらか である. 構造因子のうち, 振幅の比較的大きい次 数の構造因子の符号を適当に組み合わせて，(19)式 から $\rho(x)$ を計算する方式である.

\section{3.リポソームの中性子散乱実験を するに当たって}

リポソームの中性子散乱実験をするに当って, 次の量をあらかじめ計算しておくことは必須であ る.

\section{1 最小運動量変化}

ギニエプロットから回転半径 $\mathrm{R}_{G}$ を求めるため には $\mathrm{R}_{G} \mathrm{Q} \min <1$ を満たす $\mathrm{Q}$ 領域のデータが取 れていなければならない，予想できるリポソーム の大きさから Q min を計算しておくことが必要 である. 例えば半径 $100 \AA$ 位のものであれば 0.01 $\AA^{-1}$ 以下のデータがとれるようになっていなけれ ばならない。

\section{2 散乱強度}

$\mathrm{Q} \rightarrow 0$ 外挿の散乱強度は

$$
I(0)=C(\bar{\rho} V)^{2} \propto C \cdot M \cdot \bar{\rho}^{2}
$$

と現わされる.ここに $\mathrm{C}, \bar{\rho}, \mathrm{V}, \mathrm{M}$ はそれぞれ濃 度, コントラスト, 粒子の体積および分子量であ る. 手持ちの試料で解析可能な充分な散乱強度が 得られるか,この式から見積もっておく必要があ る. コントラストは(5)式を使って求められる.

解析に充分な散乱強度を得るための測定必要時 間は装置の性能に依存する。例えば，日本原子力 研究所 3 号炉ガイドホールに設置されている東大 物性研所有の SANS-U での実験を想定する。コ ントラストの単位を $\mathrm{D}_{2} \mathrm{O}$ と $\mathrm{H}_{2} \mathrm{O}$ の分子平均散 乱能の差 $\Delta=0.06966 \times 10^{-12} \mathrm{~cm}^{-3}$ を $1 \mathrm{con}^{-}$ trast と定義すると濃度 $\mathrm{mg} / \mathrm{ml}$, 分子量を $\mathrm{kD}$ で 示すと

$$
I(0)=100(\mathrm{mg} / \mathrm{ml})(\mathrm{kD})(\text { contrast })^{2}(23)
$$

あると充分なデータが 1 時間以内の測定時間で得 られる.

\section{4. おわりに}

リポソームを想定しながら中性子散乱実験を行 う人がなるべく役立つような内容を盛り込んでみ ました．今まで一度も中性子散乱実験を行ったこ とがない方もこの機会に実験を検討されることを お勧めいたします。

この小文がそのためのお手伝いになれば幸いで あります.

\section{文 献}

1) L. A. Feigin and D. I. Svergun, Structure Analysis by Small-Angle X-Ray and Neutron Scattering, (1987) Plenum Press, New York

Sow-Hsin Chen and Tsang-Lang Lin, Colloidal Solutions, Methods of Experimental Physics, Neutron Scattering Vol. 23 Part B, (1987) Academic Press, Ed. by D. L. Price \& K.Skold

2) F. Farsaci, M. E. Fontanella, G. Salvato, F. Wanderlingh, R. Giordano \& U. Wanderlingh, Phys. Chem. Liq., 20 (1989) 205 （受付 1997 年 9 月 1 日 掲載決定 9 月 13 日） 
Table 1 Neutron Atomic Scattering Length and X-ray Atomic Form Factor of the Elements of Main Compositions of Lipid

\begin{tabular}{l|c|c}
\hline \multicolumn{1}{c|}{ Element } & $\begin{array}{c}\text { Atomic scattering length } \\
\left(10^{-12} \mathrm{~cm}\right)\end{array}$ & $\begin{array}{c}\text { Atomic form factor } \\
\left(10^{-12} \mathrm{~cm}\right)\end{array}$ \\
\hline Hydrogen & -0.3742 & 0.28 \\
Deuterium & 0.6671 & 0.28 \\
Carbon & 0.6651 & 1.69 \\
Nitrogen & 0.940 & 1.97 \\
Oxygen & 0.5804 & 2.25 \\
\hline
\end{tabular}

目を見張るものがあり，これまでの中性子散乱研 究利用分野の内訳を大きく塗り替えてしまった. なぜこうなったかを一言で言い表すなら，中性子 は水素原子を明瞭に見ることができるプローブで あったということである. リポソームの構造研究 における中性子散乱の役割もまた同様であろう。

以下, 中性子散乱の基礎事項を述べた後, リポ ソームの構造研究における中性子散乱実験デー夕 の解析およびモデル計算のエッセンスを紹介す る.

\section{2. 中性子散乱}

\section{1 中性子}

中性子は電荷を持たない, 重さが水素の原子核 とほとんど同じ重さの粒子である. そのため物質 に入射した中性子は電子の影響を受けることなく 原子核に接近し, 原子核と相互作用し, 散乱され る（中性子は磁気モーメントを有するので磁性体 では原子の磁気モーメントとも相互作用するが, リポソームではそれはないのでこの小文ではこれ については触れない). 散乱の程度を示す量が原 子散乱長である. Table 1 に脂質を構成する主な 原子の原子散乱長を示してある.比較のために X 線の原子形状因子を長さの次元で示しておく.

この表から次のことがいえる.

1）原子散乱長は中性子を波として考えたとき の振幅に相当するものである. 中性子散乱強度は 振幅の自乗で表わされるので, 原子の種類による 散乱の効果の違いを直感的に捕えるには, 各原子 毎に原子散乱長および原子形状因子をそれぞれ自
乗してみるとよい. X 線に較べ, 中性子では水素 が他の炭素や酸素と同程度に散乱に寄与をしてい ることが明確にわかる、X 線では水素の寄与は酸 素の約 $1 / 100$ である.

2) 水素と重水素では核構造が異なるためそれ ぞれ原子散乱長が異なる. 中性子散乱では, 水素 を重水素で置換することで特定の水素位置を標識 できることになる。

3）水素の原子散乱長が負であるのは, 中性子 が水素原子核に捕獲され位相が $180^{\circ}$ ずれた波と して再放出されるためである.これは後述するが, このために水と重水とで中性子散乱能が大きく異 なることになり, リポソームの溶媒（水）に対す るコントラストを自由に変えられる中性子散乱実 験の大变有利な特徵の 1 つとなっている.

4）ド・ブロイ波としての中性子のエネルギー (E) と波長 $(\lambda)$ の関係は $\mathrm{E} \lambda^{2}=\mathrm{h} / \mathrm{m}$ と表わされ る.ここで $\mathrm{h}$ はプランク定数, $\mathrm{m}$ は中性子の質 量である. 中性子の重さは水素の原子核とほとん ど同じであるため, $\lambda=5 \AA$ の性子のエネルギー は約 $3 \mathrm{meV}$ と小さく, $\lambda=5 \AA$ の中性子で化学結 合を切るには余りにも小さいエネルギーなので, 実験に際して, リポソーム試料に長時間中性子を 照射しても放射線損傷で試料が傷むことはない。

\section{2 中性子小角散乱}

平均直径が $10 \sim 1,000 \AA$ 程度の粒子が均一媒質 に分散すると, それによる散乱が生ずる。これを 小角散乱と呼ぶ。

中性子小角散乱を考えるとき, 分散粒子を連続体 とみなし, 粒子構成原子の散乱長を局所体積 v (原 
子間距離でつくる容積よりは大きく, 観測したい 分解能よりは小さい体積）で積分した量 $\rho(\mathrm{r})$ を 局所散乱長密度と定義する.

$$
\rho(r)=\frac{1}{V} \int_{V} \mathrm{~b}_{i}(r) \mathrm{d} v
$$

$\rho(\mathrm{r})$ を用いると, 小角散乱強度は,

$$
I(Q)=\left[\left|\int_{V}\left(\rho(r)-\rho_{s}\right) \exp (\mathrm{i} Q \cdot r) \mathrm{d} v\right|^{2}\right]
$$

と表される.ここで $\rho \mathrm{s}$ は粒子を取り除いた均一 媒質の $\rho \mathrm{S}(\mathrm{r})$ である. また, $\mathrm{Q}$ は試料と中性子と の間での運動量変化で, その大きさ $\mathrm{Q}$ は中性子 の波長を $\lambda$, 散乱角を $2 \theta$ とすると, $(4 \pi / \lambda) \sin \theta$ と表わされる.

局所散乱長密度 $\rho(\mathrm{r})$ は 2 つ項に分離できる.

$$
\rho(r)=\hat{\rho}+\rho_{F}(r)
$$

ここで $\hat{\rho}$ は粒子平均散乱長で, $\hat{\rho}=(\Sigma \mathrm{bi}) / \mathrm{V}$ で 表される. 和は粒子を構成する全原子の中性子散乱 長について行い, $\mathrm{V}$ は 1 粒子の体積である. $\rho_{F}(\mathrm{r})$ は̂かからゆらぎで, 粒子全体で積分すると $0 に$ なる.つまり

$$
\int \rho_{F}(r) \mathrm{d} v=0
$$

式(2)の被積分項は式(3)を用い

$$
\bar{\rho}=\hat{\rho}-\rho_{s}
$$

と書き替えられ, 散乱強度は

$$
I(Q)=\left[\int_{V}\left|\left(\bar{\rho}+\rho_{F}(r)\right) \exp (\mathrm{iQ} \cdot r) \mathrm{d} v\right|^{2}\right](6)
$$

となる. 粒子と均一媒質との平均散乱能の差をコ ントラスト $\bar{\rho}$ と呼ぶ.

均一媒質中に分散している粒子からの散乱を考 える小角散乱では, 散乱強度はコントラストの関 数となる.

さて均一媒質として水を考え, $\mathrm{H}_{2} \mathrm{O}$ と $\mathrm{D}_{2} \mathrm{O}$ の混 合割合を変化させると式(5)の $\rho \mathrm{s}$ は変化する. 具 体的には $\mathrm{H}_{2} \mathrm{O}$ の $\rho \mathrm{s}$ は $-0.00562 \times 10^{-12} \mathrm{~cm} \AA^{-3}$, $\mathrm{D}_{2} \mathrm{O}$ の $\rho \mathrm{s}$ は $0.06404 \times 10^{-12} \mathrm{~cm}^{-3}$ で $\mathrm{D}_{2} \mathrm{O} /$ $\mathrm{H}_{2} \mathrm{O}$ 混同割合を $\mathrm{X}$ とすると

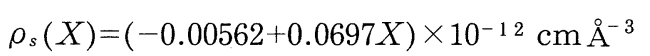

となる. そこで X を変化させると, $\rho \mathrm{s}$ が変化し, その結果散乱強度が変化する. ちょうど, 分散粒 子の異なるコントラスト断面を観測していること になり, 詳細な構造解析が可能となる.この方法 はコントラスト変化法と呼ばれ, 中性子小角散乱 法による生体物質 (タンパク質, 核酸, 生体膜な ぞ）や高分子の構造解析における常套手段となっ ている. 式(6)は Q の小さい領域では近似的に

$$
I(Q)=(\bar{\rho} V)^{2} \exp \left(-R_{G}{ }^{2} Q^{2} / 3\right)
$$

と書ける.これはギニエ則と呼ばれる式で, $\mathrm{R}_{G} \mathrm{Q}<1$ が成り立つ $\mathrm{Q}$ の領域でのみ有効である. ここで $\mathrm{R}_{G}$ は

$$
R_{G}{ }^{2}=\frac{1}{\bar{\rho} V} \int r^{2}\left(\rho_{F}(r)+\bar{\rho}\right) \mathrm{d} v
$$

と表され, 回転(慣性) 半径と呼ばれる量である. 式(9)は

$$
\begin{aligned}
& R_{G}{ }^{2}=R_{G V}{ }^{2}+\frac{1}{\bar{\rho}} \cdot \alpha \\
& R_{G V}{ }^{2}=\frac{1}{V} \int r^{2} \mathrm{~d} v \\
& \alpha=\frac{1}{V} \int \rho_{F}(r) \cdot r^{2} \mathrm{~d} v
\end{aligned}
$$

と書き替えられる. $R_{G}{ }^{2}$ を $1 / \bar{\rho}$ でプロットすると 縦軸との切点から $R_{G V}{ }^{2}$, 直線の傾きから $\alpha$ が求 められる. $R_{G V}$ はコントラスト無限大の回転半径 つまり幾何学的回転半径である. $\alpha$ は $\rho_{F}(r)$ の 2 次モーメントで分散粒子の構成元素の分布を反映 している. $\alpha$ が正となるのは分散粒子の外側の散 乱長密度が内側より大きいこと, 負となるのはそ の逆, そして, ゼロとなるのは, 分布が一様であ ることを意味する. 水素原子の散乱長は負である から, 粒子の外側に内側より多く水素原子が集ま ると， $\alpha$ が負となる. $\rho(r)$ の中心と分子の中心 が一致していない場合は式(10)に $\beta(1 / \bar{\rho})^{2}$ の項が加 わり, $R_{G}{ }^{2}$ の $1 / \bar{\rho}$ プロットは 2 次曲線となる. 曲 率 $\beta$ は, $\rho(r)$ の中心と分子の中心のずれを意味 


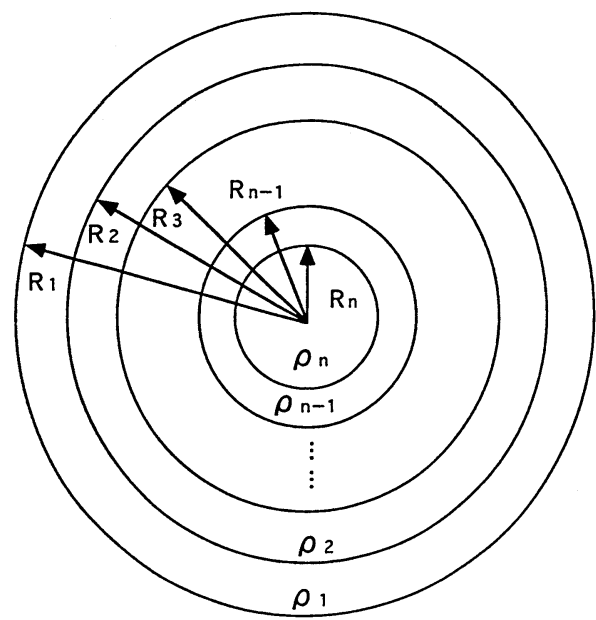

Fig. 1 The shell structure of $n$ layers

する. 実験的に $\beta$ を求めて定量的な議論をするた めには，コントラストの小さい条件で測定をする 必要がある.

\section{3 散乱強度}

\section{3.1 一様な球}

中性子散乱強度の一般式は(2)で得られる。

散乱体が一様な球の場合の散乱強度は(2)式を球 座標系に変換し

$$
\rho(r)=\left\{\begin{array}{l}
1, \mathrm{r} \leq R \\
0, \mathrm{r}>R
\end{array}\right\}
$$

として積分を行うと

$$
I(Q)=\phi^{2}(Q R)
$$

と求まる.

ここで

$\phi(Q R)=3[\sin (Q R)-Q R \cos (Q R)] /(Q R)^{3} \quad(13)$

である.

\subsection{2 球殼構造}

リポソームの構造は第一近似として, Fig. 1 に 示すような $\mathrm{n}$ 層からなる球壳構造を有している.

$$
\rho(r)=\left\{\begin{array}{c}
0, \mathrm{r}>R_{1} \\
\rho_{1}, \quad R_{2}<r \leq R_{1} \\
\rho_{2}, \quad R_{3}<r \leq R_{2} \\
\vdots \\
\rho_{n}, 0<r \leq R_{n}
\end{array}\right\}
$$

このような球殻構造の散乱強度は次の様に求め られる。一番外側の殼からの寄与は全球が $\rho_{1}$ の ものから直径 $R_{2}$ の部分をくり抜いたもの

$$
\rho_{1}\left[R_{1}^{3} \phi\left(Q R_{1}\right)-R_{2}^{3} \phi\left(Q R_{2}\right) /\left(R_{1}^{3}-R_{2}^{3}\right)\right]^{2} \quad \text { (15) }
$$

となる.

この操作を繰り返して $n$ 層からなる殼構造は $I(Q)=$

$$
\begin{gathered}
{\left[\rho_{n} \phi(Q R n)+\sum_{i=2}^{n} \rho_{i-1}\left\{R_{i-1}^{3} \phi\left(Q R_{i-1}\right)\right.\right.} \\
\left.\left.-R_{i}^{3} \phi\left(Q R_{i}\right)\right\} /\left(R_{i-1}^{3}-R_{i}^{3}\right)\right]^{2}
\end{gathered}
$$

と表わされる.

\section{3 .3 球以外の構造}

球以外の構造, 例えば楕円体, 円筒状について は参考文献に表になっているのでそれを参考にし て欲しい1).

ただし，楕円体等の款構造は(2)式の積分が形状 に応じた特殊関数を含み, 球壳の様に簡単に行え ないので(13)式のように書き下すことができない. しかし, 考え方は同じで一番外側の款からの寄与 は全体から内側の殼をくり抜いたものとして計算 すればよい。

\section{4 粒子間相互作用}

前説で述べた散乱強度式は 1 粒子からの散乱強 度であり, 実験的には希薄溶液からの散乱強度が これに相当する．濃度が増すと粒子間相互作用に よる散乱寄与が無視できなくなる，粒子間相互作 用による散乱の寄与は系が複雑なため厳密解を得 るのは不可能であり, 以前から種々の近似を用い て解かれ議論されてきていた。

筆者らは F. Fansaci らの提出している式(2)を 用いて粒子間相互作用をとり入れて，これまで中 性子小角散乱実験デー夕を解析しており, 満足い く結果が得られているのでそれを紹介する. 


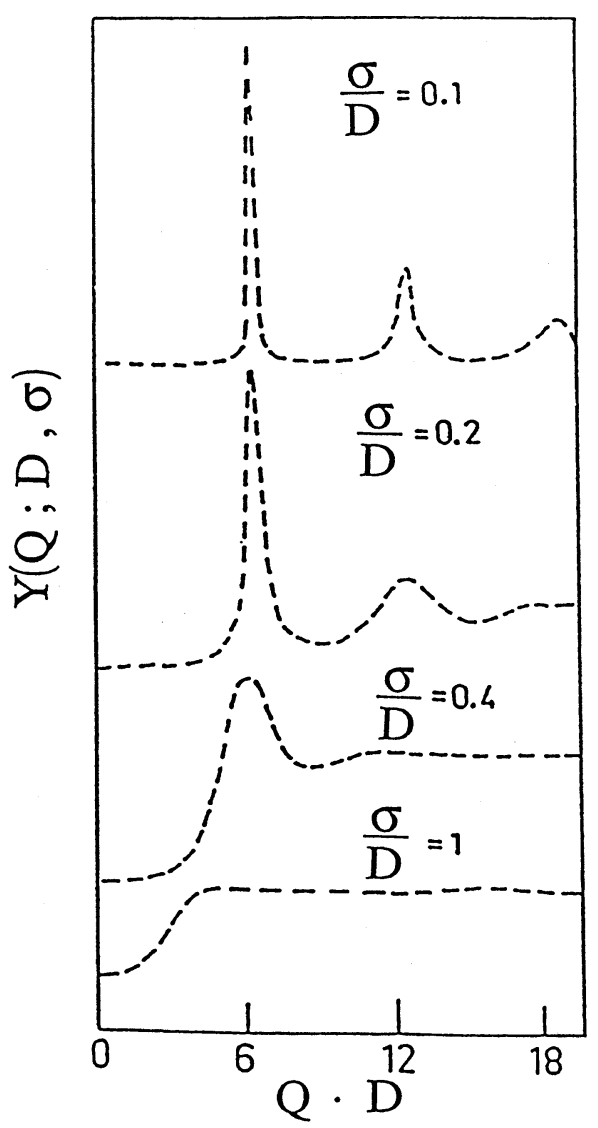

Fig. 2 Interparticle interaction at various $\sigma /$ $\mathrm{D}$ values

$\mathrm{Y}(\mathrm{Q} ; \mathrm{D}, \sigma)=$

$$
\frac{1-H(Q, \sigma) \cdot \cos (Q D)}{1-2 \cdot H(Q, \sigma) \cdot \cos (Q D)+H^{2}(Q, \sigma)}(17)
$$

ここで

$$
H(Q, \sigma)=\exp \left(-\mathrm{Q}^{2} \sigma^{2}\right) / 4
$$

である.

彼等は 2 つのパラメーター D・ $\sigma$ を用いる.こ こで D は粒子間の平均距離， $\sigma$ はそれのゆらぎ である、 $\sigma / \mathrm{D}$ が 0 ということはゆらぎの全くな い状態結晶を表し $\sigma / \mathrm{D}$ が大きくなるにつれ液体 状になる， $\sigma \mathrm{D}=2 \pi$ に液体で見れるハローが現わ れる表式になっている，Fig. 2 に $\sigma / \mathrm{D}$ を変化さ せた時の粒子間相互作用を表現する式(17)の結果を

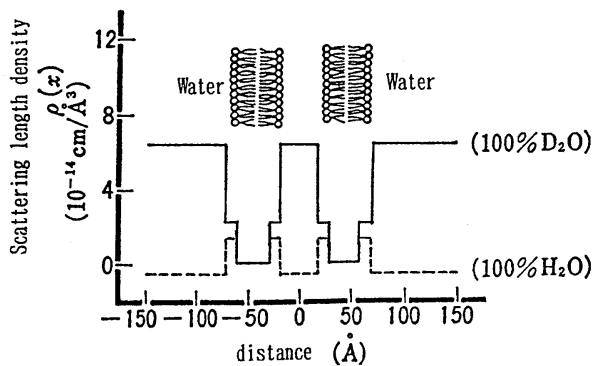

Fig. 3 Membrane structure represented by neutron scattering length density

示す.

\section{5 膜の中性子散乱}

リポソームの溶液散乱から得られる構造情報の 分解能は, $2 \pi / Q$ である. リポソームを構成する 脂質分子の詳細を知るためには, 溶液散乱から得 られる結果は粗過ぎる分解能である. リポソーム を凝集させ中性子散乱実験を行うと, 膜構造から の中性子回折像が得られる.このデー夕解析から は脂質分子の構造情報が得られる.

膜構造の基本は脂質二重層という周期構造であ り，回折現象の面からみると Bragg 反射が起こ り，すでに述べてきたのと若干異なる解析法がと られる. しかし，この周期性による Bragg 反射 は X 線回折法でも同様に生じる現象であるが, コントラスト変化法が中性子散乱法では，X 線に 比べて膜構造研究でも有利に使える特徵がある. 中性子散乱能を用いて, 膜構造のモデルを描いた のが Fig. 3 である. 中性子散乱構造因子は次式 で書ける.

$$
F(h)=2 \int_{0}^{d / 2} \rho(x) \cdot \cos (2 \pi h x / d) \mathrm{d} x \quad \text { (18) }
$$

$\mathrm{F}(\mathrm{h})$ は次数 $\mathrm{h}$ の構造因子, $\rho(x)$ は実空間で, 位置 $x$ での散乱能, $\mathrm{d}$ は二重層膜に垂直方向の一 周期距離である.

(18)式のフーリエ変換をとると(19)式になるので,

$$
\rho(x)=\frac{F(0)}{d}+\frac{2}{d} \sum_{h=1}^{n} F(h) \cos \left(\frac{2 \pi h x}{d}\right)
$$

$\mathrm{F}(\mathrm{h})$ が得られれば $\rho(x)$ を計算することがで 
きる. $\mathrm{F}(\mathrm{h})$ は中性子散乱実験の Bragg 反射強 度から求められる. 次数 h の Bragg 散乱強度 I(h) とすると，(20)式となる.

$$
I(h) \propto|F(h)|^{2}
$$

一般に, $F(h)$ は複素数で, 振幅と位相因子が含 まれる. しかし, (20)式でわかるように, 実験で得 られるのは振幅の 2 乗した值で, 位相因子は直接 求まらない，位相因子を求める 1 つの方法はパ ターソン関数,

$$
P(x)=\frac{2}{d} \sum_{h=1}^{n}|F(h)|{ }^{2} \cos \left(\frac{2 \pi h x}{d}\right) \quad \text { (21) }
$$

を計算することである.ここで，フーリエ係数は 求められるが, 得られる結果は, すべての原子間 の相関を原点の周囲に平行移動した図形であり, 解釈はそれほど容易ではない，簡単な方法として 用いられるのは試行錯誤法である. 構造に対称中 心があると, 位相因子は $(+)$ か $(-)$ のどちらか である. 構造因子のうち, 振幅の比較的大きい次 数の構造因子の符号を適当に組み合わせて，(19)式 から $\rho(x)$ を計算する方式である.

\section{3.リポソームの中性子散乱実験を するに当たって}

リポソームの中性子散乱実験をするに当って, 次の量をあらかじめ計算しておくことは必須であ る.

\section{1 最小運動量変化}

ギニエプロットから回転半径 $\mathrm{R}_{G}$ を求めるため には $\mathrm{R}_{G} \mathrm{Q} \min <1$ を満たす $\mathrm{Q}$ 領域のデータが取 れていなければならない，予想できるリポソーム の大きさから Q min を計算しておくことが必要 である. 例えば半径 $100 \AA$ 位のものであれば 0.01 $\AA^{-1}$ 以下のデータがとれるようになっていなけれ ばならない。

\section{2 散乱強度}

$\mathrm{Q} \rightarrow 0$ 外挿の散乱強度は

$$
I(0)=C(\bar{\rho} V)^{2} \propto C \cdot M \cdot \bar{\rho}^{2}
$$

と現わされる.ここに $\mathrm{C}, \bar{\rho}, \mathrm{V}, \mathrm{M}$ はそれぞれ濃 度, コントラスト, 粒子の体積および分子量であ る. 手持ちの試料で解析可能な充分な散乱強度が 得られるか,この式から見積もっておく必要があ る. コントラストは(5)式を使って求められる.

解析に充分な散乱強度を得るための測定必要時 間は装置の性能に依存する。例えば，日本原子力 研究所 3 号炉ガイドホールに設置されている東大 物性研所有の SANS-U での実験を想定する。コ ントラストの単位を $\mathrm{D}_{2} \mathrm{O}$ と $\mathrm{H}_{2} \mathrm{O}$ の分子平均散 乱能の差 $\Delta=0.06966 \times 10^{-12} \mathrm{~cm}^{-3}$ を $1 \mathrm{con}^{-}$ trast と定義すると濃度 $\mathrm{mg} / \mathrm{ml}$, 分子量を $\mathrm{kD}$ で 示すと

$$
I(0)=100(\mathrm{mg} / \mathrm{ml})(\mathrm{kD})(\text { contrast })^{2}(23)
$$

あると充分なデータが 1 時間以内の測定時間で得 られる.

\section{4. おわりに}

リポソームを想定しながら中性子散乱実験を行 う人がなるべく役立つような内容を盛り込んでみ ました．今まで一度も中性子散乱実験を行ったこ とがない方もこの機会に実験を検討されることを お勧めいたします。

この小文がそのためのお手伝いになれば幸いで あります.

\section{文 献}

1) L. A. Feigin and D. I. Svergun, Structure Analysis by Small-Angle X-Ray and Neutron Scattering, (1987) Plenum Press, New York

Sow-Hsin Chen and Tsang-Lang Lin, Colloidal Solutions, Methods of Experimental Physics, Neutron Scattering Vol. 23 Part B, (1987) Academic Press, Ed. by D. L. Price \& K.Skold

2) F. Farsaci, M. E. Fontanella, G. Salvato, F. Wanderlingh, R. Giordano \& U. Wanderlingh, Phys. Chem. Liq., 20 (1989) 205 （受付 1997 年 9 月 1 日 掲載決定 9 月 13 日） 